\title{
Transfer of Cyst(e)ine and Methionine across the Human Placenta
}

\author{
Gerald E. Gaull, ${ }^{[29]}$ Niels C. R. Räihä, Seppo SaArikoski, and John A. Sturman \\ Department of Pediatric Research, New York State Institute for Basic Research in Mental Retardation, Staten Island, New York; Department \\ of Pediatrics and Clinical Genetics Center, Mount Sinai School of Medicine of the City University of New York, New York, New York, \\ USA; and Departments of Medical Chemistry and Obstetrics and Gynaecology of the University of Helsinki, Helsinki, Finland
}

\begin{abstract}
Extract
After intravenous loads in pregnant women, L-methionine, L-leucine, and L-ornithine were transferred from maternal to fetal plasma against a two- to threefold difference in initial concentration. Cyst(e)ine is unique among the free amino acids of plasma in that its basal concentration in maternal plasma was equal to or greater than that in fetal plasma. Furthermore, after intravenous loads with L-cystine or L-cysteine, total cyst(e)ine (cystine and cysteine) was transferred less readily to the fetal plasma. Although the concentrations of cystine in the fetal plasma continued to rise in the face of rapidly falling concentrations of cystine in the maternal plasma, at no time during the experiment did the concentration of cystine in fetal plasma exceed that in the maternal plasma. When D-cystine was administered intravenously to a mother, in amounts equimolar with L-cystine, the transfer of D-cystine was not measurable.
\end{abstract}

\section{Speculation}

Cyst(e)ine is the end-product of the transsulfuration pathway, which transfers the sulfur from the 4-carbon skeleton of methionine to the 3-carbon skeleton of serine. Methionine-activating enzyme, the first enzyme on this pathway, is inhibited by cyst(e)ine $[2,5,20]$. It is also allosteric [19], a characteristic often associated with negative feedback inhibition. Cystathionase, which cleaves cystathionine to cysteine and $\alpha$-ketobutyrate and is the last enzyme on this pathway, is absent from the liver and brain of the human fetus. Therefore, we postulate that the special mechanism for the transfer of cyst(e)ine across the human placenta is an adaptation to control the transfer of sufficient maternal cyst(e)ine for synthesis of protein and glutathionine without undue inhibition of the activation of methionine to $S$-adenosylmethionine, a compound involved in important synthetic reactions.

\section{Introduction}

Cystathionase [23], the last enzyme on the pathway of transsulfuration of methionine to cysteine, cleaves cystathionine with production of cysteine and $\alpha$-ketobutyrate (Fig. 1). In previous studies, we have shown that cystathionase activity is virtually absent from human fetal liver and brain $[6,16]$, although there is considerable activity in human fetal kidney [7]. Human fetal liver does not contain enzymatically inactive precursor protein, immunologically related to mature human hepatic cystathionase, which suggests that human fetal liver does not synthesize more than trace amounts of the intact enzyme [12]. The results from limited num- 


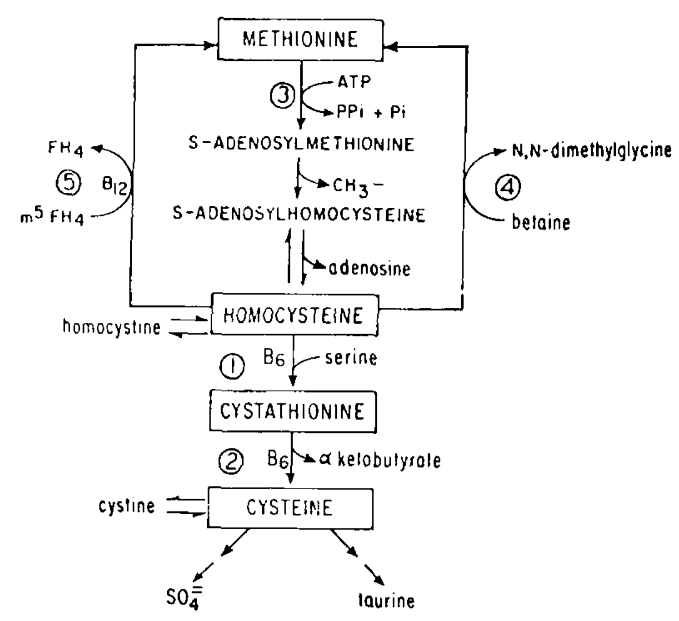

Fig. 1. The transsulfuration pathway. (1): cystathionine synthase; (2): cystathionase; (3): methionine-activating enzyme; (4): betaine-homocysteine methyltransferase; (5): $N^{5}$-methylte trahydrofolate $\left(\mathrm{m}^{5} \mathrm{FH}_{4}\right)$-homocysteine methyltransferase.

bers of liver samples obtained from premature and full term infants, who died shortly after birth, suggested that this activity is initiated some time after birth $[6$, 16] and after the methyltransferases related to the metabolism of homocysteine [7]. This confers a special importance on cysteine in the fetus for, at least in liver and in brain, it cannot be synthesized from methionine. We suggested that cyst(e)ine may be an essential amino acid for liver and for brain in the developing human until sometime after birth $[6,16]$.

Therefore, we have examined the difference in concentration of methionine and of cyst(e)ine in human fetal and maternal plasma, as well as their transfer into fetal plasma after intravenous infusion into the mother. To our surprise, we found that the concentration of cyst(e)ine in fetal plasma, in contrast to all other free amino acids in plasma, was equal to or lower than the concentration of cyst(e)ine in maternal plasma. We suggest that the transfer of cyst(e)ine from mother to fetus is controlled by a mechanism for placental transfer which is different from the other plasma amino acids.

\section{Materials and Methods}

The pregnant women participating in these experiments were healthy and underwent abortion by hysterotomy from the 16 th-22nd week of gestation for social or psychological reasons [25]. Preoperative medications included: pethidine, 50-75 mg; Phenergan, $35 \mathrm{mg}$; and atropine, $0.5-0.8 \mathrm{mg}$, intramuscularly. Anesthesia was induced with 250-440 $\mathrm{mg}$ Pentothal, intravenously, and was maintained with $\mathrm{N}_{2} \mathrm{O}_{2}$. Scoline was used as muscle relaxant.

After the uterus and amniotic sac were opened, the internal carotid artery of the fetus was cannulated with a nylon catheter [26], and zero time blood samples were drawn simultaneously from the mother (1-5 $\mathrm{ml})$ and from the fetus $(0.5 \mathrm{ml})$. After this, an amino acid load was administered, intravenously, to the mother in $20 \mathrm{ml}$ of $0.9 \% \mathrm{NaCl}$ solution over a $30-\mathrm{s}$ interval. Cystine was dissolved in a minimum amount of $1 \mathrm{~N} \mathrm{NaOH}$ before being made up to volume by saline. Blood samples were taken simultaneously from the mother and from the fetus at 5-min intervals during the next $20-30 \mathrm{~min}$. A total of 20 separate experiments were performed, with at least 2 for each amino acid. Monitoring of the fetal heart beat and previous experience with measurement of placental circulation by one of us (N. C. R. R.) [14] assured us that the placental circulation was intact during the course of the experiments. Additional samples of blood from the mother were taken at 30,45 , and $60 \mathrm{~min}$, although the fetus and placenta were removed at $20 \mathrm{~min}$ in most experiments, but no later than $30 \mathrm{~min}$ in any experiment.

In some experiments, small aliquots of blood were taken for measurement of hematocrit and $\mathrm{pH}$; the remainder was prepared for amino acid analysis [15] and stored at $-20^{\circ}$ until analyzed. In no case was a specimen stored for more than 2 months, and, in every case, the fetal and maternal blood samples were prepared and analyzed in parallel on an amino acid analyzer fitted with tandem columns operating simultaneously. All the samples from a specific experiment were analyzed on the same machine utilizing the same batch of ninhydrin and eluting buffers. Peak integration and further calculations of amino acid concentrations were performed by on-line computer [27]. Total cyst(e)ine was determined by the method of Brigham et al. [1]. Amino acid analysis of tissues was performed as described previously [15].

\section{Results}

A striking new finding in our study was that the concentration of cyst(e)ine in fetal plasma was equal to or lower than the concentration of cyst(e)ine in maternal plasma, whereas, for all other free amino acids, the fetal concentration was higher than the maternal concentration. The general observation of the higher concentration of amino acids in fetal plasma had been made in a number of laboratories $[8,11,18,21,22]$. 


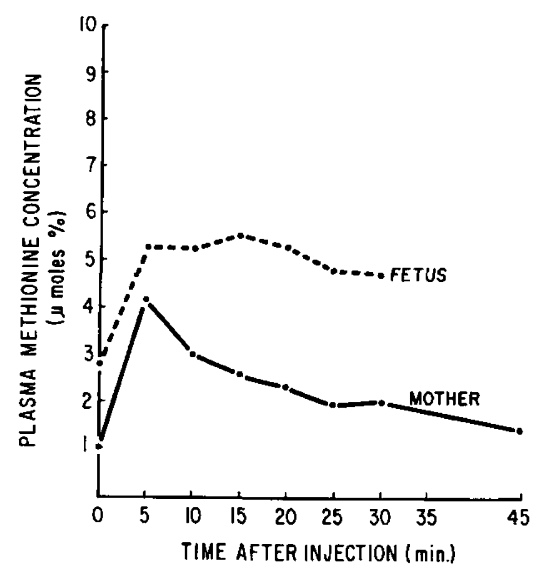

Fig. 2. Fetal and maternal plasma concentrations of methionine after intravenous administration of $\mathrm{L}$-methionine $(0.5 \mathrm{mmol})$ to the mother.

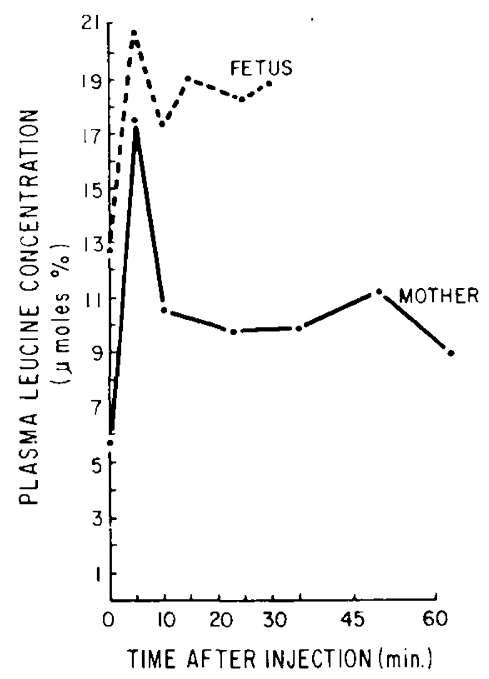

Fig. 3. Fetal and maternal plasma concentrations of leucine after intravenous administration of $\mathrm{L}$-leucine $(1.25 \mathrm{mmol})$ to the mother.

That cysteine was an exception was previously unappreciated. The data of Young [21] in the guinea pig shows this, although she did not remark upon it. We have also recently found this in the pregnant monkey [17].

After intravenous administration to the mother, Lmethionine was transferred from maternal to fetal plasma against a threefold difference in concentration (Fig. 2). L-Leucine, transported by the same carrier system in most tissues [10], behaved similarly (Fig. 3). L-Ornithine, transferred by the dibasic amino acid carrier system [13], was similar to the neutral amino acids, methionine and leucine. At zero time, the concentration of ornithine in fetal plasma was twice that in maternal plasma (Fig. 4). Despite this difference, ornithine was readily transferred into the fetal circulation. Although this experiment was not repeated with a smaller dose of ornithine, the concentration of ornithine in the fetal plasma was rising sharply at a time that the maternal concentration was falling, and it exceeded the maternal concentration for the last half of the experiment. This would be unlikely in the case of simple diffusion, and, although a temporary concentration difference might be found with simple diffusion, the maintenance of this difference (zero time concentrations) could not be explained by simple diffusion. Of course, when a compound is injected as a bolus, as it was in these experiments, the concentration in the maternal circulation may well rise above that in the fetal circulation before the first sampling at $5 \mathrm{~min}$. In the pregnant ewe, the transfer characteristics of ornithine appear different from that of leucine [21], a possible species difference.

The findings after intravenous administration of $\mathrm{L}$ cystine and of L-cysteine were quite different from those of L-methionine, of L-leucine, and of L-ornithine. First, the concentration of cystine in maternal plasma was equal to or greater than that in fetal plasma. This was the only free amino acid measurable in plasma for which this was true. Second, at no time after intravenous administration of L-cystine (Fig. 5, $a$ and $b$ ) did the concentration of cystine in the fetal plasma exceed that in the maternal plasma. However, the concentration of cystine in the fetal plasma continued to rise in the face of rapidly falling concentrations of cystine in the maternal plasma.

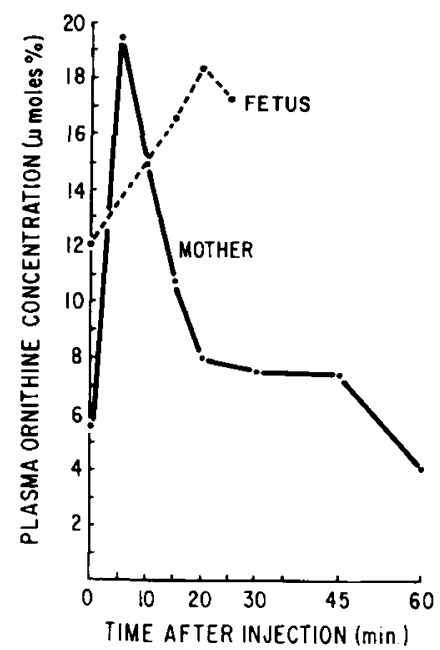

Fig. 4. Fetal and maternal plasma concentrations of ornithine after intravenous administration of L-ornithine $(2.5 \mathrm{mmol})$ to the mother. 

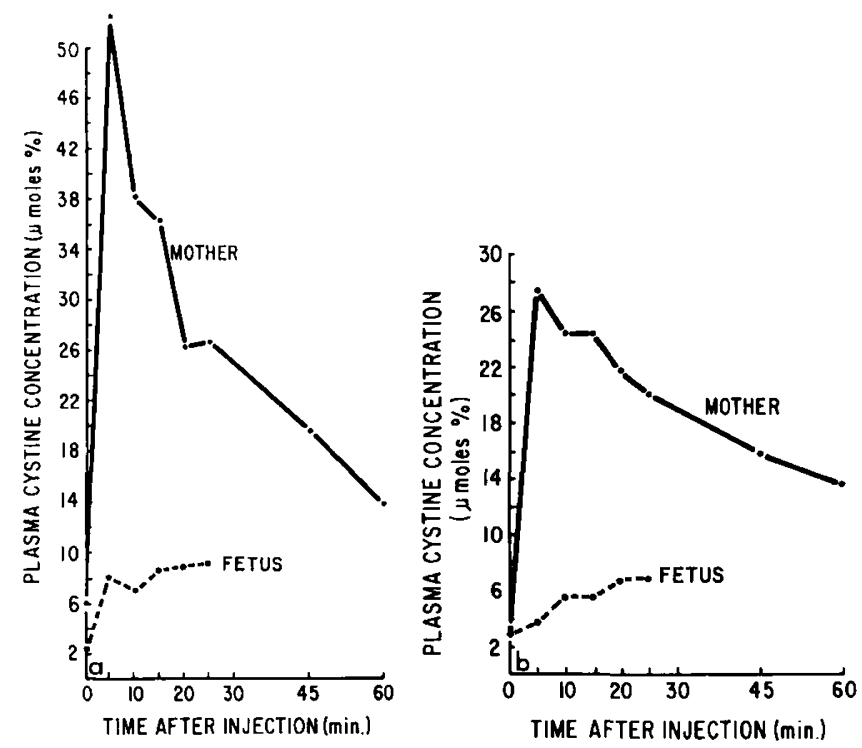

Fig. 5. Fetal and maternal plasma concentrations of cystine after intravenous administration of L-cystine $(2.5 \mathrm{mmol})$ to the mother.

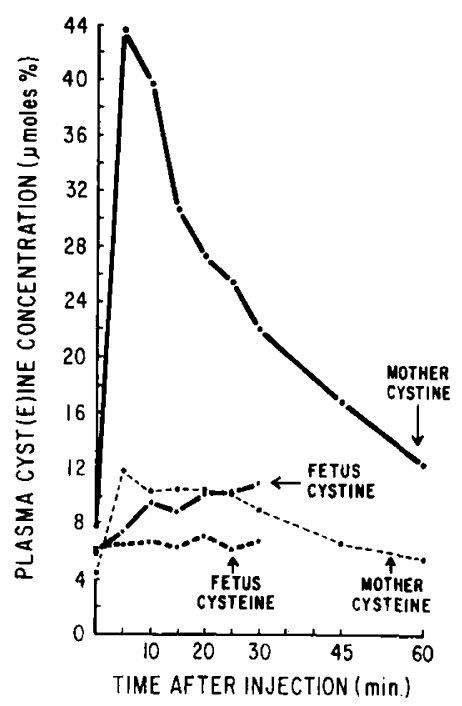

Fig. 6. Fetal and maternal plasma concentrations of cystine and cysteine after intravenous administration of L-cystine (2.5 mmol) to the mother.

In another experiment with L-cystine, total cyst(e)ine was measured in order to determine whether failure to measure the sulfhydryl form (cysteine) had given misleading results (Fig. 6). The concentration of cysteine in the fetal plasma at zero time was higher in this particular experiment than the concentration of cysteine in the maternal plasma. However, the concentration of cystine was again greater in the maternal plasma, and the concentration of total cyst(e)ine was exactly the same in the two circulations. After this load of L-cystine, the change in concentration of cystine was essentially the same as in the previous experiment with L-cystine.

$\mathrm{L}$-Cysteine $\cdot \mathrm{HCl}$, in amounts of sulfur equimolar with the loads of L-cystine, was also administered. In this experiment, the concentrations of both cystine and cysteine in maternal plasma were equal to those in fetal plasma at zero time (Fig. 7). By the time of the first sample $(5 \mathrm{~min})$, the concentrations of cystine and cysteine in maternal blood were equimolar. This may have been because the amino acid solution was prepared in advance in order to be sterilized, and it is likely that equilibrium between cystine and cysteine had been reached before administration. More important, the transfer of cystine and cysteine to the fetal circulation after administration of $\mathrm{L}$-cysteine $\cdot \mathrm{HCI}$ was similar to the experiments with L-cystine and different from those with methionine, leucine, and ornithine.

An experiment with D-cystine was performed to obtain further evidence that the transfer of cystine was not by simple diffusion. When D-cystine was administered to a mother, in amounts equimolar with L-cystine, the transfer of D-cystine was far slower; indeed there was no change in the concentration of cystine in fetal plasma during the experiment (Fig. 8). In this experiment, D-cystine was measured by the change in cystine, as the amino acid analyzer is unable to separate stereoisomers. The base-line value for $\mathrm{L}$-cystine has not been subtracted and inspection of the zero time concentration of cystine (i.e., no superimposed D-cystine) shows another instance in which there was a higher concentration of cystine in maternal plasma than in fetal plasma.

A similar experiment was attempted using D-methionine and measuring its appearance in the fetal plasma

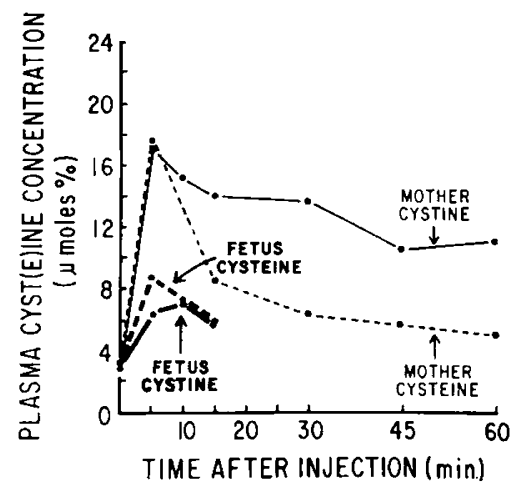

Fig. 7. Fetal and maternal plasma concentrations of cystine and cysteine after intravenous administration of L-cysteine $\cdot \mathbf{H C l}(5.0$ $\mathrm{mmol}$ ) to the mother. 


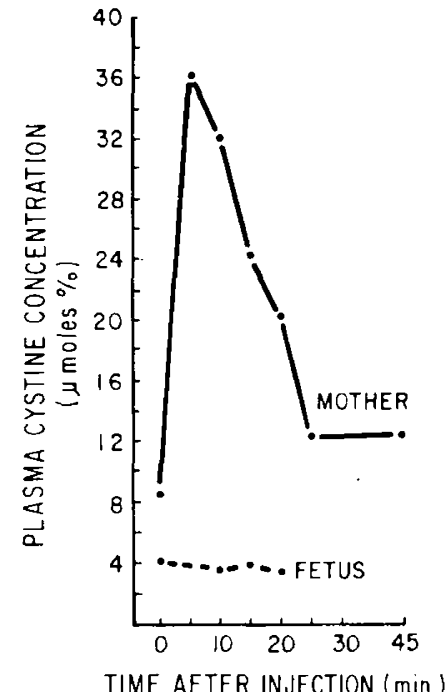

Fig. 8. Fetal and maternal plasma concentrations of cystine after intravenous administration of D-cystine $(2.5$ mmoles $)$ to the mother.

by measurement of the increase in methionine. As is the case with cystine, the amino acid analyzer cannot separate the stereoisomers. To our surprise, we found that the transfer of D-methionine, measured in this way, was apparently as rapid as that of L-methionine. If what we measured in the chromatographic position of methionine was really D-methionine, it would mean that $\mathrm{D}$-methionine is transferred from mother to fetus as readily as $\mathrm{L}$-methionine. This would suggest that methionine is transferred across the placenta by simple diffusion, which is inconsistent with its uniformly higher fetal concentration. An alternative explanation is that $\mathrm{D}$-methionine was rapidly converted to its $\mathrm{L}$ isomer. We believe this to be the likely explanation, since it is known that animal tissues have the ability to isomerize $\mathrm{D}$-methionine, via its $\mathrm{D}$-amino acid oxidase, more readily than most $\mathrm{D}$-amino acids [10]. This ability is low for D-cystine [10].

\section{Discussion}

Our data for L-methionine, L-leucine, and L-ornithine, taken together with considerable other data from a number of laboratories $[3,4,8,9,11,17,21,22]$, is compatible with the hypothesis that, in general, amino acids are transferred from mother to fetus by a process of active transport, i.e., carrier-mediated, saturable, energy-dependent, stereospecific, and operating against a chemical gradient.

In striking contrast is our data for cyst(e)ine, which is unique among the free amino acids of the plasma in not having a higher concentration in fetal plasma than in maternal plasma. Indeed, in some instances we have observed, the concentration of cystine is higher in maternal plasma than in fetal plasma (Figs. 5, 6, and 8). However, this may be a difference in the ratio of cystine/cysteine, which is usually $2 / 1$ or $3 / 1$ in the adult [1], but which might well be reversed in the higher reducing milieu of the fetus. Our experiments in which we measured the concentration of both cystine and cysteine in fetal and in maternal plasma (Figs. 6 and 7) suggest that this might be the case, i.e., that the concentration of total cyst(e)ine is equal in both circulations. This point requires further study. In any case, the transfer of cyst(e)ine across the placenta from mother to fetus is under a separate and special transfer mechanism in that a fetal/maternal concentration ratio greater than 1 is not maintained, and it is transferred less readily than other L-amino acids. In addition, the slower rate of transfer of D-cystine and the fact that the concentration of L-cystine after an L-cystine load is still rising in the fetal plasma at a time when the concentration in the maternal plasma is falling further suggests that the transfer process is not one of simple diffusion. The transfer of cyst(e)ine is thus a carrier-mediated transfer, but one in which a fetal/maternal concentration ratio greater than $l$ is not maintained.

It is conceivable that this failure to maintain a higher concentration in fetal plasma in the case of cyst(e)ine is because of a rapid uptake of cyst(e)ine by the placenta or by the fetal tissues. In the present experiments, amino acid analysis of fetal organs taken 20-30 min after infusion of cyst(e)ine into the mother failed to demonstrate a significant accumulation of cyst(e)ine. In previous experiments, the in vitro uptake of ${ }^{35}$ S-cysteine by human fetal tissues was less than the uptake of ${ }^{35} \mathrm{~S}$-methionine [6]. Furthermore, in the pregnant rhesus monkey, in which the transfer of methionine and cystine across the placenta resembles that of the human, the in vivo uptake of ${ }^{35}$ S-cystine by placenta and fetal organs after injection into the maternal circulation was meager compared with the uptake of ${ }^{35}$ S-methionine similarly injected [17]. When ${ }^{35}$ S-cystine was injected into the fetal circulation, there was a considerable uptake by fetal tissues [17], which demonstrates that there is little difficulty in the transfer of cystine between the fetal blood and the various tissues of the fetus. Furthermore, whereas ${ }^{35} \mathrm{~S}$-methionine injected into the pregnant monkey showed rapid isotopic equilibrium (15-20 min) between mother and fetus, the specific radioactivity of ${ }^{35}$ S-cystine similarly 
injected had not reached equilibrium between maternal and fetal circulation after $1 \mathrm{hr}$.

Taken together, the evidence suggests that cyst(e)ine is transferred less readily than other amino acids from mother to fetus. Furthermore, the absence of a higher concentration of cyst(e)ine in fetal plasma is not because it is transferred by simple diffusion, but is, rather, a unique ability of the placenta to control the movement of cyst(e)ine from mother to fetus by a process of mediated transfer.

\section{Summary}

Cyst(e)ine is transferred across the human placenta by a process which is carrier mediated. In contrast to the other free amino acids, however, the placenta does not maintain a difference in plasma concentration of cyst(e)ine which is greater in the fetus than the mother.

\section{References and Noles}

1. Brigham, M. P., Stein, W. H., and Moore, S.: The concentration of cysteine and cystine in human blood plasma. J. Clin. Invest., 39: 1633 (1960)

2. Cantoni, G. L.: Activation of methionine for transmethylation. J. Biol. Chem., 189: 745 (1951).

3. Christensen, N., And Streicher, J. A.: Association between rapid growth and elevated cell concentrations of amino acids. I. In fetal tissues. J. Biol. Chem., 175: 95 (1948),

4. Felig, P., Kim, Y. J., Lynch, V., and Hendler, R.: Amino acid metabolism during starvation in human pregnancy. $J$ Clin. Invest., 51: 1195 (1972).

5. Finkelstein, J. D., AND MudD, S. H.: Transsulfuration in mammals: The methionine-sparing effect of cystine. J. Biol. Chem., 242: 873 (1967).

6. Gaull, G. E., Sturman, J. A., and Räihä, N. G. R.: Development of mammalian sulfur metabolism: Absence of cystathionase in human fetal tissue. Pediat. Res., 6: 538 (1972).

7. Gaull, G. E., von Berg, W., Räihä, N. C. R., ANd Sturman, J. A.: Develoment of methyltransferase activities of human fetal tissues. Pediat. Res., 7: 527 (1973)

8. Glendening, M. D., Margolis, A. J., and Page, E. W.: Amino acid concentrations in fetal and maternal plasma. Amer. $J$ Obstet. Gynecol., 81: 591 (1961)

9. Litonjua, A. D., Canlas, M., Soliman, J., and Paulino, D. Q.: Uptake of $\alpha$-aminoisobutyric acid in placental slices at term. Amer. J. Obstet. Gynecol., 99: 242 (1967).

10. Meister, A.: Biochemistry of the Amino Acids, Ed. 2, Vol. I (Academic Press, New York, 1965).

11. Page, E. W., Glendening, M. B., Margolis, A., and Harper, H. A.: Transfer of $D$ - and L-histidine across the human placenta. Amer. J. Obstet. Gynecol., 73: 589 (1957).

12. Pascal, T. A., Gillam, B. M., and Gaull, G. E.: Cys tathionase: Immunochemical evidence for absence from human liver. Pediat. Res., 6: 773 (1972).

13. Rosenberg, L. E., Downing, S. J., and Segal, S.: Competitive inhibition of dibasic amino acid transport in rat kidney. J. Biol. Chem., 237: 2265 (1962).

14. Rudolph, A. M., Heymann, M. A., Terano, K. A. W., Barrett, C. T., ANd RäIHÄ, N. C. R.: Studies on the circulation of the previable human fetus. Pediat. Res., 5: 452 (1971).

15. Sturman, J. A., Cohen, P. A., and Gaull, G. E.: Effects of deficiency of vitamin $B_{6}$ on transsulfuration. Biochem. Med., 3: 244 (1969).

16. Sturifan, J. A., Gaull, G., and Rälhä, N. C. R.: Absence of cystathionase in human fetal liver: Is cystine essential? Science, 169: 74 (1970).

17. Sturman, J. A., Niemann, W. H., and Gaull, G. E.: Metabolism of ${ }^{35} \mathrm{~S}$-methionine and ${ }^{35} \mathrm{~S}$-cystine in the pregnant rhesus monkey. Biol. Neonate, in press.

18. Szabo, A. J., and Grimaldi, R. D.: The metabolism of the placenta. Advan. Metab. Disord., 5: 185 (1970).

19. Tallan, H. H., Cohen, P. A., and Gaull, G. E.: Allosteric properties of rat liver methionine-activating enzyme (Abstract). Fed. Proc., 31: 576, (1973).

20. Tallan, H. H., Cohen, P. A., Sturman, J. A., and Gaull, G. E.: Unpublished observations.

21, Young, M.: Placental transport of free amino acids. In: J. H. P. Jonxis, H. K. A. Visser, and J. A. Traveistra: Metabolic Processes in the Foetus and Newborn Infant, p. 97 (H. E. Stenfert Knoese, N. V., Leiden, The Netherlands, $1971)$.

22. Young, M., And Prenton, M. A.: Maternal and fetal plasma amino acid concentrations during gestation and in retarded fetal growth. J. Obstet. Gynaec. Brit. Commonw., 76: 333 (1969).

23. Cystathionase has been used rather than L-homoserine hydrolyase (deaminating) EC 4.2.1.15, because it is the transsulfuration function we are studying.

24. This work was briefly presented at the Society of Pediatric Research, Washington, D.C., May 1972, and at the Sir Joseph Barcroft Centenary Symposium of the Physiological Society, Cambridge, England, July 1972.

25. Informed consent was obtained in experiments involving human subjects.

26. Nylon intravenous catheter, $0.63 \mathrm{~mm}$ OD, N. B205, Portex, Ltd., Hythe, Kent, England.

27. Infotronics CRS-1000 on-line computer, Austin, Tex.

28. Support for this work was shared by the New York State Department of Mental Hygiene, the Lalor Foundation, National Institutes of Health Clinical Genetics Center Grant No. GM 19443-02, and the Association for the Aid of Crippled Children.

29. Requests for reprints should be addressed to: Gerald Gauli, M.D., Department of Pediatric Research, New York State Institute for Basic Research in Mental Retardation, 1050 Forest Hill Road, Staten Island, New York, N. Y. 10314 (USA).

30. Accepted for publication June 22, 1973. 